\title{
OPTIMALISASI SISHANKAMRATA MELALUI PENERAPAN LIMA PILAR TOTAL DEFENCE SEBAGAI UPAYA MEWUJUDKAN NEGARA INDONESIA YANG BERDAULAT
}

\author{
Wahyu Beny Mukti Setiyawan \\ Fakultas Hukum Universitas Islam Batik Surakarta \\ muktibeny@gmail.com \\ Bagus Hanindyo Mantri \\ Fakultas Hukum Universitas Sebelas Maret Surakarta \\ bdjoshx@yahoo.com \\ Amir Junaidi \\ Fakultas Hukum Universitas Islam Batik Surakarta \\ amirjunaidi495@gmail.com
}

\begin{abstract}
Abstrak
Menurut data statistik kependudukan dunia megatakan bahwa Negara Indonesia memliki jumlah penduduk terbanyak ke-empat, sebanyak 237,6 juta jiwa. Indonesia juga merupakan negara kepulauan yang terbesar di dunia (the biggest archipelago state in the world). Keadaan tanahnya yang subur, dan terletak diantara dua benua serta dua samudera besar, membuat posisi geografis Indonesia sangat strategis. Hal ini menyebabkan banyak negara lain di dunia sejak dulu ingin menguasai bumi nusantara ini. Pembukaan UUD NRI 1945 merupakan sumber dorongan terbesar tekad bangsa Indonesia untuk mencapai suatu tujuan bangsa. Salah satu upayanya adalah dengan memperkuat pertahanan dan keamanan Negara Kesatuan Republik Indonesia. Namun, pada penerapanya saat ini SISHANKAMRATA belum berjalan secara optimal dalam melindungi dan mempertahankan kedaulatan negara Indonesia. Hal ini disebabkan oleh beberapa faktor seperti rendahnya kualitas SDM, lemahnya ketahanan ekonomi Indonesia, kurang harmonisnya hubungan TNI dan Polri, rendahnya stabilitas politik, dan pudarnya rasa nasionalisme pada generasi muda. Untuk itu diperlukannya sebuah Kebijakan Pembangunan Kekuatan Pertahanan mencakup pembangunan kemampuan nasional. Konsep Optimalisasi SISHANKAMRATA dengan 5 Pilar Total Defence System sebagai pembaharuan dan penguatan dari pertahanan nasional dengan menggabungkan konsep SISHANKAMRATA Indonesia dengan konsep Total Defence System Singapura yang selaras dengan cita-cita Dasar Negara. Jenis penelitian yang akan digunakan penulis dalam penelitian ini adalah penelitian yuridis-normatif dengan menggunakan metode pendekatan perundang-undangan (statue-approach), pendekatan konseptual (conseptual approach), dan pendekatan komparatif (comparative approach), Konsep Optimalisasi SISHANKAMRATA dengan lima Pilar Total Defence System memberikan solusi yang solutif dalam awal langkah baru menyongsong negara Indonesia yang Berdaulat dengan Pengoptimalan Sistem Pertahanan Nasional Indonesia dalam Kerangka SIHANKAMRATA.
\end{abstract}

Kata kunci: SISHANKAMRATA,Sumber daya Manusia.

\begin{abstract}
Abstrak
According to world population statistics, Indonesia has the fourth largest population, 237.6 million. Indonesia is also the largest archipelago country in the world (the biggest archipelago state in the world). The condition of the fertile land, and is located between two continents and two large oceans, makes Indonesia's geographical position very
\end{abstract}


strategic. This has caused many other countries in the world to have always wanted to dominate this archipelago. The preamble to the 1945 Constitution of the Republic of Indonesia is the greatest source of encouragement for the Indonesian nation's determination to achieve a national goal. One of the efforts is to strengthen the defense and security of the Republic of Indonesia. However, in its current implementation, SISHANKAMRATA has not been running optimally in protecting and defending the sovereignty of the Indonesian state. This is due to several factors such as the low quality of human resources, the weak resilience of the Indonesian economy, the lack of harmony between the TNI and the Police, low political stability, and a fading sense of nationalism in the younger generation. For this reason, a Defense Force Development Policy is needed which includes building national capabilities. The concept of optimizing SISHANKAMRATA with 5 Pillars of Total Defense System as a renewal and strengthening of national defense by combining the Indonesian SISHANKAMRATA concept with the Singapore Total Defense System concept which is in line with the Basic ideals of the State. The type of research that the writer will use in this research is juridical-normative research using the statue-approach method, the conceptual approach, and the comparative approach, the SISHANKAMRATA Optimization Concept with the five Pillars of Total Defense. The system provides a solution that is a solution in the beginning of a new step towards welcoming the Sovereign Indonesian state by optimizing the Indonesian National Defense System in the SIHANKAMRATA Framewor.

Keywords: SISHANKAMRATA,Human Resources.

\section{A. PENDAHULUAN}

Menurut data statistik kependudukan dunia mengatakan bahwa Negara Indonesia memliki jumlah penduduk terbanyak ke-empat. ${ }^{1}$ Jumlah penduduk Indonesia sebanyak 237,6 juta jiwa. ${ }^{2}$ Indonesia juga merupakan negara kepulauan yang terbesar di dunia (the biggest archipelago state in the world). Indonesia terdiri dari 17.499 pulau dari Sabang hingga Merauke. Luas total wilayah Indonesia adalah 7,81 juta $\mathrm{km}^{2}$ yang terdiri dari 2,01 juta $\mathrm{km}^{2}$ daratan, 3,25 juta $\mathrm{km}^{2}$ lautan, dan 2,55 juta $\mathrm{km}^{2}$ Zona Ekonomi Eksklusif (ZEE). ${ }^{3}$ Keadaan tanahnya yang subur, dan terletak diantara dua benua serta dua samudera besar, membuat posisi geografis Indonesia sangat strategis. Hal ini menyebabkan banyak negara lain di dunia sejak dulu ingin menguasai bumi nusantara ini. Kondisi geografis yang sangat

1 Google Public Data World Development Indicators: Data Statistik Publik Dunia Tentang

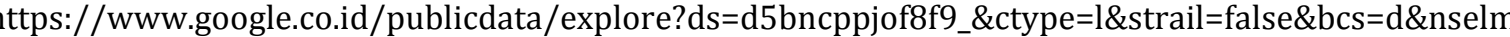
$=$ h\&met_y=sp_pop_totl\&scale_y=lin\&ind_y=false\&rdim=region\&idim=country:IDN:CHN:USA:IND\&ifdi $\mathrm{m}=$ region\&hl=en\&dl=en\&ind=false\&icfg\&iconSize=0.5 pada 12 Sepember 2020 pukul 22.01

${ }^{2}$ Penduduk Indonesia menurut Provinsi 1971, 1980, 1990, 1995, 2000 dan 2010 diakses dari https://www.bps.go.id/linkTabelStatis/view/id/1267 pada tanggal 27 September 201722.39

${ }^{3}$ Indonesia Merupakan Negara Kepulauan Yang Terbesar Di Dunia diakses dari http://bphn.go.id/news/2015102805455371/INDONESIA-MERUPAKAN-NEGARA-KEPULAUAN-YANGTERBESAR-DI-DUNIA, pada tanggal 12 September 202017.16 


\section{Borneo Law Review Vol.4 No.2 \\ Desember 2020}

menguntungkan serta diperindah oleh adanya keanekaragaman suku, etnis, budaya, agama, bahasa, serta adat-istiadat, sangatlah menggiurkan bagi bangsa-bangsa lain. ${ }^{4}$ Dibalik segala kelebihan yang dimiliki, Negara Indonesia memerlukan sistem yang dapat melindungi serta mempertahankan negara.

Pembukaan UUD 1945 merupakan sumber dorongan tekad bangsa Indonesia untuk mencapai suatu tujuan bangsa. Alinea keempat pembukaan Undang-Undang Dasar Negara Republik Indonesia 1945 tertulis bahwa :

"Membentuk suatu Pemerintah Negara Indonesia yang melindungi segenap bangsa Indonesia dan seluruh tumpah darah Indonesia dan untuk memajukan kesejahteraanumum, mencerdaskan kehidupan bangsa, dan ikut melaksanakan ketertiban dunia."

Berdasarkan hal tersebut, dapat diketahui dengan seksama dalam menjalankan tujuan kehidupan bangsa, Indonesia harus dapat melindungi segenap bangsa Indonesia dan seluruh tumpah darah Indonesia. Salah satu upayanya adalah dengan memperkuat pertahanan dan keamanan Negara Kesatuan Republik Indonesia. Sistem Pertahanan dan Keamanan Rakyat Semesta (untuk selanjutnya disebut dengan SISHANKAMRATA) merupakan upaya pengerahan seluruh kekuatan nasional secara total dan integral, dengan mengutamakan kekuatan dalam mempertahankan kemerdekaan dan kedaulatan Negara Kesatuan Republik Indonesia dalam menjamin keutuhan bangsa serta mengamankan segala upaya dalam mencapai tujuan nasionalnya. SISHANKAMRATA melibatkan segenap elemen yang dimiliki oleh bangsa Indonesia sebagai bagian dari usaha mempertahankan kedaulatan dan kokohnya Negara Kesatuan Republik Indonesia.

Namun pada penerapanya saat ini, SISHANKAMRATA belum berjalan secara optimal dalam melindungi dan mempertahankan kedaulatan negara Indonesia. Berdasarkan pasal 30 ayat (1) Undang-Undang Dasar Negara Republik Indonesia Tahun 1945 tertulis bahwa "Tiap-tiap warga negara

\footnotetext{
${ }^{4}$ Pentingnya Peranan Sishankamrata Yang Dilandasi Wawasan Kebangsaan Dalam Menjaga Kedaulatan Negara Kesatuan Republik Indonesia diakses dari http://www.geocities.ws/nunk_shion/paper/sisham.html, diakses pada tanggal 27 Agustus 2020 23.47
} 
berhak dan wajib ikut serta dalam usaha pertahanan dan keamanan negara.". dan dalam pasal 30 ayat (2) Undang-Undang Dasar Negara Republik Indonesia Tahun 1945 pun ditetapkan bahwa rakyat sebagai kekuatan pendukung.

Terdapat juga beberapa penyebab lain belum optimalnya SISHANKAMRATA yaitu: pertama, belum terintegrasinya peraturanperaturan perundang-undangan mengenai pertahanan, keamanan, serta peran dan fungsi TNI dan Polri. Kedua, pengabaian dan belum padunya pemikiran di antara kalangan sipil mengenai bagaimana membangun hubungan sipil-militer yang ideal. Ketiga, masih adanya pergolakan politik di beberapa wilayah Indonesia yang menjurus pada gerakan-gerakan separatisme, digunakannya militer untuk kegiatan-kegiatan di luar peran tradisionalnya seperti civic-missions, memberi dampak negatif terhadap hubungan sipil-militer. Keempat, semakin bertambahnya peran militer di luar peran tradisional mereka untuk menangkal serangan luar, dikenal dengan konsep operasi militer di luar perang konvensional (military operations other than war), bukan saja berpengaruh dalam teori dan politik hubungan sipil-militer di berbagai negara, melainkan juga di Indonesia. ${ }^{5}$

Pancasila sebagai ideologi negara merupakan penggalian dari nilainilai bangsa. Salah satunya terkandung pada sila ketiga yaitu persatuan Indonesia. Sehingga jika dikaitkan dengan pertahanan dan keamanan negara, dapat dipahami bahwa dalam menjalankan tujuan-tujuan bangsa, rakyat Indonesia harus bersatu padu dan bersama dalam menjaga kedaulatan negara. Pada masa sekarang, ancaman terhadap negara bukan hanya dari bidang militer saja melainkan juga dari non militer, seperti masalah-masalah human security. Dari pemahaman tersebut, dapat diketahui bahwa syaratsyarat hubungan yang harmonis dan baik adalah adanya kesetaraan, keseimbangan, dan yang lebih penting adalah adanya kepercayaan, tujuan, dan nilai-nilai yang ingin dicapai bersama dan digunakan untuk patokan dari

${ }^{5}$ Anwar, Dewi Fortuna.2002. Gus Dur Versus Militer : Studi tentang Hubungan Sipil-Militer di Era Transisi, Jakarta:PT. Grasindo. hlm 15-16 


\section{Borneo Law Review Vol.4 No.2 \\ Desember 2020}

tiap-tiap kelompok, pihak ataupun lembaga. ${ }^{6}$

Konsep human security secara ekspansif meliputi dimensi ekonomi, kesehatan, pangan, lingkungan hidup, individu, komunitas, dan politik. Ancaman utama bagi human security adalah kemunculan isu-isu transnasional seperti HIV-AIDS, penyelundupan obat terlarang, terorisme, kemiskinan global, dan degradasi lingkungan hidup. Isu-isu ini cenderung tidak dapat diselesaikan secara satu pihak saja melainkan dibutuhkan suatu cara pandang kerja sama antar berbagai lembaga/pihak. ${ }^{7}$ Karena pada dasarnya semua bidang yang akan diatasi adalah saling berhubungan dan berkaitan. Hubungan militer-sipil saling berkaitan. Keadaan perekonomian yang struktur dan pertumbuhannya bergerak pun juga akan akan mempengaruhi bidang seperti sosial dan psikologi. ${ }^{8}$ Hal inilah yang dimiliki oleh sistem pertahanan dan keamanan Singapura namun belum diterapkan oleh Indonesia. Sehingga penulis mengagas adanya optimalisasi SISHANKAMRATA melalui penerapan lima pilar Total Defence yaitu dengan cara mengkolaborasikan kelebihan Total Defence ke dalam SISHANKAMRATA. Kolaborasi kedua sistem ini dipandang dapat merealisasikan optimalisasi SISHANKAMRATA, serta Negara Indonesia yang benar-benar berdaulat dapat terwujud.

\section{B. METODE PENELITIAN}

1. Jenis Data

Jenis bahan hukum yang digunakan dalam penelitian ini adalah dengan menggunakan Bahan Hukum Primer, Sekunder dan tersier. ${ }^{9}$

a. Bahan hukum primer yang dimaksud meliputi:

1) Undang-Undang Dasar Negara Republik Indonesia Tahun 1945.

${ }^{6}$ Soyomukti, Nurani.2016. Pengantar Sosiologi : Dasar Analisis, Teori, dan Pendekatan Menuju Analisis Masalah-Masalah Sosial, perubahan Sosial, dan Kajian-Kajian Strategis, Yogyakarta: Ar-Ruzz Media. hlm. 268

${ }^{7}$ Widjajanto, Andi. 2006. Transnasionalisasi Masyarakat Sipil, Jakarta:Fisip UI Pres. hlm. 14-15

${ }^{8}$ Basri,Faisal dan Haris Munandar. 2009. Lanskap Ekonomi Indonesia : Kajian dan Renungan Terhadap Masalah-masalah Struktural, Transformasi Baru, dan prospek Perekonomian Indonesia, Jakarta:Kencana Prenada Media Group. hlm. 72

9Ibid., Peter Mahmud Marzuki. hlm. 141, menjelaskan bahwa bahan hukum primer merupakan bahan hukum yang hukum yang bersifat autoritatif yang artinya memiliki otoritas. Risalah dalam pembuatan perundang-undangan dan putusan-putusan hakim. 
2) Undang-Undang Nomor 34 Tahun 2004 tentang TNI.

3) Undang-Undang Nomor 3 Tahun 2002 tentang Pertahanan Negara.

4) Undang-Undang Nomor 2 Tahun 2002 tentang Kepolisian NRI.

b. Bahan hukum sekunder yang digunakan oleh peneliti, meliputi :

Literatur-literatur yang terkait dengan permasalahan yang dikaji berasal dari buku-buku, sejarah SISHANKAMRATA di Indonesia dan perjalanannya, Undang-Undang Nomor 20 Tahun 1982 tentang Ketentuan-ketentuan Pokok Pertahanan Keamanan Negara Republik Indonesia, pendapat ahli hukum dari segi kepustakaan, artikel dan internet.

c. Bahan Hukum tersier yang penulis gunakan dalam penelitian ini berupa kamus, baik kamus hukum maupun kamus bahasa Indonesia dan kamus lainnya yang dibutuhkan.

\section{PEMBAHASAN}

1. Problematika Penerapan Sistem Pertahanan dan Keamanan Rakyat Semesta

Pada hakikatnya sistem pertahanan dan keamanan Negara Indonesia adalah segala upaya pertahanan yang bersifat semesta. Sistem pertahanan tersebut lebih dikenal dengan Sistem Pertahanan dan Keamanan Rakyat Semesta (SISHANKAMRATA). Sifat kesemestaannya dimana dalam penyelenggaraan sistem pertahanan negara didasarkan pada kesadaran akan hak dan kewajiban seluruh warga negara serta keyakinan pada kekuatan sendiri untuk mempertahankan kelangsungan hidup bangsa dan negara Indonesia yang merdeka dan berdaulat. Kesemestaan mengandung makna pelibatan seluruh rakyat dan segenap sumber daya nasional, sarana dan prasarana nasional, serta seluruh wilayah negara sebagai satu kesatuan pertahanan yang utuh dan menyeluruh.

Bagi Indonesia, penyelenggaraan pertahanan dan keamanan

10Departemen Pertahanan Republik Indonesia II, 2008, Buku Putih Pertahanan Indonesia 2008, Jakarta, hlm. 43 
negara bukan semata-mata ditujukan untuk perang, melainkan juga untuk mewujudkan perdamaian, menjamin keutuhan Negara Kesatuan Republik Indonesia, mengamankan kepentingan nasional, serta menjamin terlaksananya pembangunan nasional. ${ }^{11}$ Sistem pertahanan dan keamanan negara yang efektif adalah pertahanan dan keamanan yang mampu menghadirkan suasana aman dan damai di mana kehidupan masyarakat berjalan secara normal, dan hubungan dengan sesama negara lain baik di kawasan maupun di luar kawasan berlangsung secara harmonis dan saling menghargai. Sebagai negara yang menganut paham negara kesejahteraan (welfare state), melindungi kedaulatan dan keutuhan Negara Kesatuan Republik Indonesia melalui optimalisasi sistem pertahanan dan keamaanan rakyat semesta merupakan salah satu langkah yang tepat guna mewujudkan tujuan dan cita-cita bangsa Indonesia. $^{12}$ Namun pada kenyataannya sistem pertahanan dan keamanan rakyat semesta sebagai konsep utama dalam menjaga kedaulatan dan keutuhan Negara Kesatuan Republik Indonesia masih belum mampu dilaksanakan secara massive dan optimal, hal tersebut dikarenakan oleh berberapa faktor, antara lain sebagai berikut :

a. Rendahnya Kualitas Sumber Daya Manusia, dalam rangka menjaga keutuhan dan kedaulatan Negara Kesatuan Republik Indonesia sumber daya manusia memegang peranan penting, khususnya dalam bidang pembangunan. Oleh karena itu dalam melaksanakan pembangunan suatu negara perlu diketahui keadaan sumber daya manusia yang ada di wilayah tersebut.

b. Lemahnya Ketahanan Ekonomi Indonesia, perekonomian memiliki peran yang vital dalam suatu negara dikarenakan jika perekonomian tidak berjalan dengan baik maka suatu negara tidak akan mampu menjalankan perannya dengan sempurna.

\footnotetext{
11Departemen Pertahanan Republik Indonesia II, Op.Cit, hlm. 45.

${ }^{12}$ Liht Aline ke 4 Pembukaan Undang-Undang Dasar Negara Republik Indonesia Tahun 1945.
} 
c. Kurang harmonisnya Hubungan TNI dan Polri, Pertahanan dan keamanan negara merupakan faktor yang sangat hakiki dalam menjamin kelangsungan hidup negara, tanpa mampu mempertahankan diri terhadap ancaman dari luar dan dalam negeri suatu negara tidak akan dapat mempertahankan keberadaannya.

d. Rendahnya Stabilitas Politik di Indonesia, politik memiliki peranan penting dalam menentukan dasar kestabilan yang terdapat dalam kehidupan berbangsa dan bernegara.

e. Pudarnya rasa nasionalisme pada generasi muda di Indonesia. Nasionalis memerupakan sebuah identitas dalam sebuah negara.

Selain dipengaruhi oleh berberapa faktor diatas, efektifitas penerapan SISHANKAMRATA juga dipengaruhi oleh berberapa kebijakan pemerintah, antara lain sebagai berikut $:^{13}$

a. Doktrin dan Strategi Penjagaan

Doktrin Pertahanan dan Strategi Pertahanan disusun untuk mensinergikan kinerja komponen Militer dan Nir Militer dalam rangka menjaga, melindungi dan memelihara kepentingan nasional Indonesia. Doktrin pertahanan merupakan keterpaduan komponen militer dan Nir Militer bersifat Dwiwarna Nusantara. Doktrin Militer bersifat Trimatra Nusantara (AD, AL, AU) sedangkan Doktrin Nir Militer bersifat Dwidarma Nusantara dari komponen cadangan dan komponen pendukung. Berdasarkan faktor-faktor yang mempengaruhi ditingkat global, regional, dan nasional disusun strategi pertahanan Negara Kesatuan Republik Indonesia berupa Strategi Penangkalan yaitu:

1) Pertahanan multilapis dengan pusat gravitasi dukungan rakyat atas peran TNI sebagai kekuatan utama yang menentukan di darat, di laut dan diudara.

\footnotetext{
13Anonim, Yuk Pertahankan Keamanan Bangsa dengan Sishankamrata, https://www.merdeka.com/pendidikan/yuk-pertahankan-keamanan-bangsa-dengansishankamrata.html, diakses pada 13 September 2020, pukul 19.55 WIB.
} 
2) Merupakan pertahanan total secara terpadu antara komponen Militer dan Nir Militer untuk menghadapi setiap bentuk ancaman.

3) Di tingkat nasional berupa jaringan terpadu Ketahanan Nasional di daerah termasuk di wilayah perbatasan dan daerah terpencil didasari semangat belanegara.

4) Di tingkat regional berupa jaringan kerjasama antara negara-negara Association of South East Asia Nations (ASEAN) dengan menggunakan komponen Militer dan Nir-Militer (ekonomi, budaya, identitas) secara terpadu dalam rangka menjaga, melindungi dan memelihara kepentingan Nasional Indonesia.

b. Kebijakan Pembangunan KekuatanPertahanan

Pembangunan kekuatan Pertahanan mencakup pembangunan kemampuan nasional di bidang pertahanan pada tingkat kebijakan maupun tingkat operasional. Pada tingkat kebijakan berupa peningkatan kemampuan birokrasi pemerintah (Departemen Pertahanan dan Departemen/Instansi lain yang terkait) dalam merumuskan keputusan politik yang terkait dengan pengelolaan pertahanan negara. Sedangkan pada tingkat operasional berupa pembangunan kekuatan komponen pertahanan, yang terdiri dari Komponen Utama/Tentara Nasional Indonesia (TNI), Komponen Cadangan, dan Komponen Pendukung. Oleh karenanya pembangunan komponen cadangan dilaksanakan secara bertahap sesuai kemampuan sumber daya yang tersedia, dengan terlebih dahulu menyusun Undang-Undang Komponen Cadangan sebagai landasan hukum pembentukan dan penggunaannya. Sedangkan pembangunan Komponen Pendukung adalah pembangunan setiap aspek kehidupan nasional yang dilaksanakan oleh departemen/instansi masing-masing yang hasilnya diarahkan untuk kepentingan pertahanan. 
c. Kebijakan Pengarahan dan Penggunaan Kekuatan Pertahanan

Pengerahan dan penggunaan kekuatan pertahanan didasarkan pada doktrin dan strategi SISHANKAMRATA yang dilaksanakan berdasarkan pertimbangan ancaman yang dihadapi Indonesia. Agar pengerahan dan penggunaan kekuatan pertahanan dapat terlaksana secara efektif dan efisien, diupayakan keterpaduan yang sinergis antara unsur militer dengan unsur militer lainnya, maupun antara kekuatan militer dengan kekuatan nir militer. Keterpaduan antara unsur militer diwujudkan dalam keterpaduan Tri-Matra, yakni keterpaduan antar kekuatan darat, kekuatan laut, dan kekuatan udara. Sedangkan keterpaduan antara kekuatan militer dan kekuatan nir militer diwujudkan dalam keterpaduan antar komponen utama, komponen cadangan, dan komponen pendukung. Keterpaduan tersebut diperlukan dalam pengerahan dan penggunaan kekuatan pertahanan, baik dalam rangka menghadapi ancaman tradisional maupun ancaman non-tradisional.

d. KebijakanPenganggaran

Keterbatasan kemampuan pemerintah dalam mengalokasikan anggaran pertahanan merupakan hambatan yang sangat signifikan bagi upaya pembangunan kekuatan maupun pengerahan dan penggunaan kekuatan pertahanan. Padahal, penentuan alokasi anggaran tidak cukup hanya berdasarkan kondisi ekonomi nasional, tetapi juga harus didasarkan pada rasio kebutuhan pertahanan yang mampu menjamin stabilitas keamanan. Oleh karenanya pengalokasian anggaran dilaksanakan berdasarkan skala prioritas secara ketat. Kedepan, diharapkan alokasi anggaran pertahanan dapat ditingkatkan secara bertahap, sekurang-kurangnya sampai dapat tercapai kekuatan pertahanan pada tingkat kekuatan pokok minimum.

e. Kebijakan Pengawasan.

Guna menjamin akuntabilitas pelaksanaan fungsi pertahanan, 
diperlukan pengawasan eksekutif maupun legislatif terhadap penyelenggaraan pertahanan negara. Pada Undang-undang Pertahanan Negara Terdapat perubahan pada komponen pertahanan negara. Beberapa komponen dalam upaya mewujudkan pertahanan nasional rakyat semesta, yaitu :

a. Tentara Nasional Indonesia sebagai komponen utama dengan didukung oleh komponen cadangan dan komponen pendukung.

b. Komponen cadangan, terdiri atas warga negara, sumber daya alam, sumber daya buatan, serta sarana dan prasarana nasional yang telah disiapkan untuk dikerahkan melalui mobilisasi guna memperbesar dan memperkuat komponen utama.

c. Komponen pendukung, terdiri atas warga negara, sumber daya alam, sumberdaya buatan, serta sarana dan prasarana nasional yang secara langsung atau tidak langsung dapat meningkatkan kekuatan dan kemampuan komponen utama dan komponen cadangan Sistem pertahanan negara dalam menghadapi ancaman nonmiliter menempatkan lembaga pemerintah di luar bidang pertahanan sebagai unsur utama, sesuai dengan bentuk dan sifat ancaman yang dihadapi dengan didukung oleh unsur-unsur lain dari kekuatan bangsa. ${ }^{14}$

Kedua, Penelitian terhadap konsep TDS (Total Defence System).Penelitian terhadap TDS ini ditujukan untuk mempelajari dan menganalisa lebih mendalam mengenai model pertahanan negara Singapura yang bernama TDS. TDS terdiri dari lima aspek pokok pertahanan, pertahanan militer, pertahanan sipil, pertahanan ekonomi, pertahanan psikologi, dan pertahanan sosial. ${ }^{15}$

\footnotetext{
14Pasal (7) dan (8) Undang-Undang Republik Indonesia No. 3 Tahun 2002 tentang PertahananNegara

15Diakses dari https://www.scdf.gov.sg/content/scdf.../total-defence.html, diakses pada 28 Agustus 201715.20
} 


\section{PENUTUP}

1. Kesimpulan

a. Pada hakikatnya sistem pertahanan dan keamanan Negara Indonesia adalah segala upaya pertahanan yang bersifat semesta. Pada hakikatnya SISHANKAMRATA sebagai konsep utama dalam menjaga kedaulatan dan keutuhan Negara Kesatuan Republik Indonesia masih belum mampu dilaksanakan secara massive dan optimal. Hal ini disebabkan oleh beberapa faktor seperti rendahnya kualitas SDM, lemahnya ketahanan ekonomi Indonesia, kurang harmonisnya hubungan TNI dan Polri, rendahnya stabilitas politik, dan pudarnya rasa nasionalisme pada generasi muda. Untuk itu diperlukannya sebuah Kebijakan Pembangunan Kekuatan Pertahanan mencakup pembangunan kemampuan nasional.

b. Konsep Optimalisasi SISHANKAMRATA dengan 5 Pilar Total Defence System sebagai pembaharuan dan penguatan dari pertahanan nasional dengan menggabungkan konsep SISHANKAMRATA Indonesia dengan konsep Total Defence System Singapura yang selaras dengan cita-cita Dasar Negara. Konsep Optimalisasi SISHANKAMRATA dengan 5 Pilar Total Defence System dapat memberikan solusi yang solutif dalam awal langkah baru menyongsong Indonesia negara yang berdaulat sebagai pengoptimalan sistem pertahanan nasional Indonesia dalam kerangka SISHANKAMRATA.

2. Saran

a. Rekonseptualisasi SISHANKAMRATA dengan 5 Pilar Total Defence System.

b. Membuat pengaturan khusus yang integral dari Pengoptimalan Sistem Pertahanan Nasional Indonesia dalam KerangkaSISHANKAMRATA.

\section{DAFTAR PUSTAKA}

\section{A. LITERASI}

Anwar, Dewi Fortuna. 2002. Gus Dur Versus Militer : Studi tentang Hubungan SipilMiliter di Era Transisi, Jakarta:PT. Grasindo.. 


\section{Borneo Law Review Vol.4 No.2 \\ Desember 2020}

Basri,Faisal dan Haris Munandar. 2009. Lanskap Ekonomi Indonesia : Kajian dan Renungan Terhadap Masalah-masalah Struktural, Transformasi Baru, dan prospek Perekonomian Indonesia, Jakarta:Kencana Prenada Media Group..

Departemen Pertahanan Republik Indonesia II, 2008, Buku Putih Pertahanan Indonesia 2008, Jakarta..

Soyomukti, Nurani.2016. Pengantar Sosiologi : Dasar Analisis, Teori, dan Pendekatan Menuju Analisis Masalah-Masalah Sosial, perubahan Sosial, dan Kajian-Kajian Strategis, Yogyakarta: Ar-Ruzz Media.

Widjajanto, Andi. 2006. Transnasionalisasi Masyarakat Sipil, Jakarta:Fisip UIPres.

\section{B. PERATURAN PERUNDANG-UNDANGAN}

Undang-Undang Dasar Negara Republik Indonesia Tahun 1945 Undang- Undang Republik Indonesia No. 34 Tahun 2004 tentang Tentara Nasional Indonesia Undang-Undang Republik Indonesia No. 3 Tahun 2002 tentang Pertahanan Negara

\section{INTERNET}

Anonim, Yuk Pertahankan Keamanan Bangsa dengan Sishankamrata, https://www.merdeka.com/pendidikan/yuk-pertahankan-keamananbangsa-dengan-sishankamrata.html, diakses pada 13 September 2020, pukul 19.55 WIB.

Google Public Data World Development Indicators: Data Statistik Publik Dunia Tentang Jumlah Penduduk Dunia Tahun 2015 diakses dari https://www.google.co.id/publicdata/explore?ds=d5bncppjof8f9_\&ctype=l \&strail=false \&bcs=d\&nselm=h\&met_y=sp_pop_totl\&scale_y=lin\&ind_y=false \&rdim=region\&idim=country:IDN:CHN:USA:IND\&ifdim=region\&hl=en\&dl=e n\&ind=false\&icfg\&iconSize $=0.5$ pada 12 Sepember 2020 pukul 22.01

Singapore Government. Singapotre Civil Defence Force. Diakses dari https://www.scdf.gov.sg/content/scdf.../total-defence.html diakses pada 27 Agustus 201713.03 